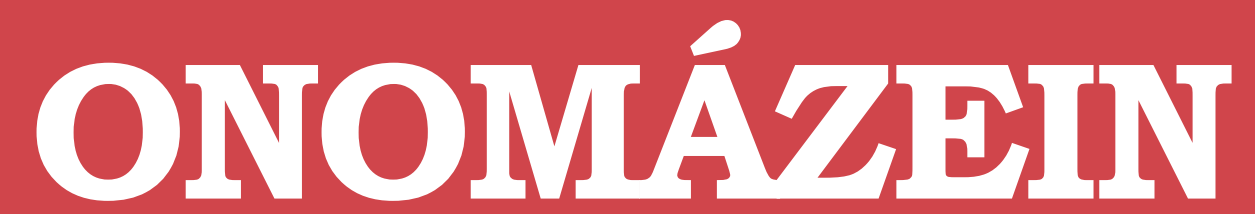

Revista de lingüística, filología y traducción
PONTIFICIA UNIVERSIDAD

\title{
¿Por qué deberían contribuir los investigadores a la revitalización de las lenguas? Revitalizar la lingüística para que sirva a la resistencia de los pueblos originarios y migrantes
}

Why should researchers contribute to the revitalization of languages? Revitalize linguistics to serve the resistance of the original and migrant peoples

\section{Joaquín José Martínez Sánchez \\ Universidad de Sevilla \\ España}

Número especial

Las lenguas amerindias en Iberoamérica: retos para el siglo XXI

2017
ONOMÁZEIN - Número Especial

Las lenguas amerindias en Iberoamérica: retos para el siglo XXI (2017): 204-223

DOI: 10.7764/onomazein.amerindias.11

\section{(c) $($ i $)$}

Joaquín José Martínez Sánchez: Proyecto Ndatiaku Tu’un Savi, Universidad de Sevilla, España. | Correo electrónico: dicciomixteco@gmail.com 


\section{Resumen}

Existe un consenso cada vez más generalizado acerca de la necesidad de transformar profundamente el escenario diseñado por la investigación académica sobre las lenguas originarias, en su mayoría gravemente amenazadas. Aunque las universidades, en general, han proporcionado descripciones complejas y detalladas de las lenguas subsistentes y de sus variantes dialectales, sin embargo, apenas han contribuido a fortalecer las capacidades de las poblaciones-objeto para resistir la globalización y convertir algunos de sus instrumentos en oportunidades, como es el caso de los medios y las redes sociales.

En el presente artículo se parte de la experiencia cosechada por el proyecto Ndatiaku Tu’un savi, que tiene como propósito cooperar a la revitalización del mixteco (tu’un savi, ‘lengua de la lluvia'), haciendo uso de las redes sociales para documentar las prácticas vernáculas en vivo, a la vez que para devolver a los hablantes indígenas el reconocimiento intercultural de sus valores.

Se propone que la investigación académica subvierta los privilegios otorgados por las culturas dominantes, hasta asumir los objetivos explícitos de los movimientos sociales y políticos por la autonomía de los pueblos originarios: la normalización de sus lenguas y la recuperación de espacios públicos como la educación o los medios sociales. En el ámbito americano, dichos objetivos se han manifestado y consolidado desde 1992 hasta la fecha.

Palabras clave: tu’un savi; lenguas originarias; lenguas en peligro; documentación; revitalización; política lingüística; medios sociales.

\section{Abstract}

There is an increasingly broad consensus on the need to profoundly transform the academic research arena into the original languages, most of which are seriously threatened. Although universities in general have provided complex and detailed descriptions of subsistent languages and their dialectal variants, however, they have hardly contributed to strengthening the capacities of the target populations to resist the globalizing tide and convert some of their instruments into opportunities, such as the media and social networks. 
This article is based on the experience gained by the Ndatiaku Tu'un Savi project, whose purpose is to cooperate with the revitalization of Mixteco (Tu'un savi, 'language of the rain'), making use of social networks to document live vernacular practices, as well as to give indigenous speakers the intercultural recognition of their values.

It is suggested that academic research should try to subvert the privileges granted by dominant cultures, and to assume the explicit objectives of social and political movements for the autonomy of native peoples: the normalization of their languages and the recovery of public spaces such as education or social media. In the American context, these objectives have been manifested and consolidated since 1992 to date.

Keywords: Tu'un savi; native languages; endangered languages; documentation; revitalization; language policy; social media. 


\section{Introducción}

La lengua mixteca (tu’un savi, 'lengua de la lluvia') es una de las sesenta lenguas minoritarias de la República Mexicana, a las que la Ley de Desarrollo Lingüístico (2003) concede carácter cooficial, junto con el castellano. En 2015, según el INEGI, el número de hablantes alcanzó el medio millón (517 665). No obstante, una serie de amenazas reales está provocando el abandono de la lengua materna, interrumpiendo su transmisión intergeneracional hasta el punto de generar un sentimiento de "autoodio" (Ninyoles, 1971) entre los hablantes más jóvenes. Además de la presión ejercida por la lengua y la cultura dominante durante cinco siglos, hay que tener en cuenta el efecto devastador de la migración forzosa que afecta prácticamente a la totalidad de las familias, precisamente en las regiones donde se había mantenido el uso de la lengua en todos los registros sociales. En consecuencia, el tu'un savi se ha extinguido en comunidades periféricas de Oaxaca, Puebla y Guerrero (grado 0 de la escala de la UNESCO, 2003; cfr. Fishman, 1991; Fishman, 2001; Lewis y Simon, 2009); ha pasado a una situación crítica en las zonas urbanas (grado 1); corre un serio peligro en zonas rurales donde el castellano es la lengua de la administración y el comercio (grados 2 y 3), y, por último, se ha hecho vulnerable (grado 4) en las regiones más apartadas y pobres del país (por distritos: la Montaña de Guerrero; Juxtlahuaca, en Oaxaca), a consecuencia de la oleada migratoria desde 1990.

La pérdida o la amenaza grave a la supervivencia de las lenguas originarias no supone, solamente, una disminución de la diversidad y del patrimonio cultural de la humanidad. Además, tiene consecuencias sobre la vida de millones de personas, debido a los efectos perniciosos de la desintegración de su mundo vital (Lebenswelt): sociedad, cultura, lengua y personalidad (cfr. Habermas, 1987, vol. II). En países donde la diversidad cultural es fruto, principalmente, de la inmigración, se contempla positivamente e incluso se justifica desde las universidades la presión sufrida por distintos grupos étnicos para que se asimilen a la cultura dominante. De esa ambigüedad ha surgido el término "aculturación" por referencia a una "realidad inevitable" (cfr. Berry, 1997).

Sin embargo, cuando hablamos de los pueblos originarios, el panorama es muy distinto. La desaparición de las lenguas y de las culturas nativas obedece a una estrategia planificada de dominio, propia de la era colonial. Mi experiencia como investigador y cooperante en el desarrollo lingüístico al servicio de las comunidades indígenas mixtecas (Guerrero, México) se refiere a esa "realidad evitable", que debe ser denunciada y confrontada (Martínez Sánchez, 2015; García Leyva, 2016).

El proyecto Ndatiaku Tu'un Savi de la Universidad de Sevilla (http://dicciomixteco.wixsite. com/ndatiaku) comenzó el segundo semestre del curso 2013/14 y continúa hasta el momento con el objetivo de promover la revitalización de las lenguas originarias a través de las redes 
sociales, centrando el foco de investigación sobre el tu'un savi. Durante nuestro camino, hemos tenido la oportunidad de conectar con otras redes activas y más potentes, cuyos objetivos hicimos nuestros: la Academia Mixteca (Ve’e Tu’un Savi), el Comité de Desarrollo Lingüístico de Guerrero, el proyecto "Activismo digital en lenguas indígenas" de Global Voices, etc. Los diferentes investigadores coincidimos en que nuestros esfuerzos siguen siendo insuficientes para afrontar las amenazas que se ciernen sobre los pueblos amerindios.

Por lo que respecta a la mayoría de las lenguas en peligro, es claro que las amenazas se intensificaron con el proceso histórico de globalización, que afecta a las identidades etnolingüísticas en todo el planeta. La lucha entre la homogeneización cultural y la resistencia de las identidades fue profetizada por Manuel Castells (1996-1998) hace apenas veinte años y no atiende solamente al escenario fabricado por las sociedades de la información y la comunicación a través de las TIC, sino que tiene que ver con los modos en que se organiza la producción y el consumo en la economía del "capitalismo canalla”, en términos de César Rendueles (2015). Sin embargo, el proceso tiene una profunda raigambre en la expansión colonizadora de las potencias europeas en el siglo XVI o quizá incluso en los imperios de la Antigüedad (cfr. Wallerstein, 1974-1989).

La denuncia de los genocidios históricos ha acompañado a la modernidad en sus distintas fases, pero ha tardado siglos en madurar. En el extremo opuesto, la figura del buen salvaje (bon savage) ha impuesto una contrafigura: un estereotipo, incluso legal, sobre cómo debería comportarse el otro para que fuera digno de compasión por el verdugo.

Como he relatado en "Ña yuvi nu iyo na yuvi” (Martínez Sánchez, 2012), los conflictos provocados por la globalización contra los pueblos amerindios se remontan al genocidio durante la conquista de América. No es posible resumir en pocas líneas el tránsito de la cultura y la lengua del ñuu savi a través de los siglos coloniales, las guerras de independencia, el liberalismo, la revolución mexicana, etc. La recuperación parcial del control del territorio por las comunidades na savi no se hizo realidad hasta los años 30 del pasado siglo, bajo la presidencia de Lázaro Cárdenas. Aun así, a partir de los años 70, estas comunidades se enfrentaron a la voracidad de las empresas madereras que esquilmaban los bosques enajenados de la protección comunitaria por leyes que los consideraban propiedad pública, es decir, patrimonio del Estado, lo cual, paradójicamente, facilitó su explotación imprudente en el marco del capitalismo estatal.

1 El proyecto se diseñó como una alternativa complementaria a las clases de lingüística general y aplicada del profesor Juan Pablo Mora en la Universidad de Sevilla, en paralelo con otro proyecto sobre la lengua de signos española. A lo largo de cuatro cursos, se ha conseguido formar un equipo permanente de colaboradores mexicanos y mixtecos: Ofelia Pineda Ruiz, Antonio Guerra Arias, Jaime García Leyva, Onésimo Cruz, entre más de una decena de contribuyentes, que protagonizan cada año las actividades del proyecto con nuevos jóvenes estudiantes sevillanos. 
A este respecto cabe subrayar las consecuencias funestas del Tratado de Libre Comercio de América del Norte (TLCAN) en 1994 y la nueva política de desamortización neoliberal, cuya respuesta proporcional fueron los movimientos indígenas y, entre ellos, el movimiento zapatista, que emprendió un nuevo proceso de reapropiación del territorio. El desafío fue aprovechado por muchos jóvenes de aquella generación (La Neta), para redefinir la identidad mexicana desde el nacionalismo republicano a la plurinacionalidad, netamente inclinada a favorecer las causas indígenas.

Aunque la cultura ñuu savi se identifica en todo México con la canción del migrante, por lo que se refiere al pueblo na savi de la Montaña, el TLCAN dio pie a una migración masiva, temporal o definitiva, de hombres, primero, y familias enteras, poco después, hacia la agroindustria en los estados del norte de México y hacia los Estados Unidos, adonde los mixtecos oaxaqueños precedieron a los guerrerenses.

En este estado de cosas, durante la última década, el gobierno se ha atrevido a hacer concesiones a compañías transnacionales para el negocio de la "nueva minería gigante",

a costa de socavar los derechos colectivos de los pueblos indígenas y campesinos, destruir extensas superficies y sus ecosistemas, consumir enormes volúmenes de agua que provocan sequías y contaminación de los mantos hídricos, además del consumo de grandes cantidades de energía eléctrica y combustible que presupone la contaminación del aire y la destrucción de otros territorios indígenas y campesinos para la construcción de hidroeléctricas y la extracción petrolera (Tlachinollan, 2010: 31).

Entre 2005 y 2010, se concedieron 250000 hectáreas con plazos de 50 años a empresas como CAMSIN (canadiense) o HOCHSCHILD (inglesa), en la región de Costa-Montaña. Desde 2012 hasta la fecha, el Consejo Regional de Autoridades Agrarias en Defensa del Territorio, con el apoyo jurídico de Tlachinollan (Centro de Derechos Humanos de la Montaña, Guerrero, México), se ha enfrentado a la creación de otras minas a cielo abierto en las regiones limítrofes de la Montaña y Costa Chica. Aunque el Registro Agrario Nacional se niega a reconocer valor legal a las declaraciones de la mayoría de entidades agrarias, así y todo, las autoridades campesinas han impedido que se ejecuten las concesiones realizadas en territorio na savi, nahua, me’phaa o ñomdaa (cfr. sobre el extractivismo en América Latina, Pineda Ruiz y otros, 2017).

También debe de ser una causa disuasoria el hecho de que los pueblos originarios de la zona hayan organizado, a lo largo de dos décadas, un sistema de policía comunitaria a través de la CRAC (Coordinadora Regional de Autoridades Comunitarias), aunque todavía no sea plenamente asumido por el Estado. Lo que para las comunidades significa mayor seguridad contra la delincuencia organizada o el narcopoder es visto desde fuera como un muro de defensa contra la enajenación forzosa del territorio para "minarlo". 
Dentro de ese universo de tensiones estructurales a que ha dado lugar el proceso de globalización, en su actual fase de despliegue neocolonial, tiene que situarse cualquier proyecto investigador sobre las lenguas originarias.

\section{La lingüística con que nacimos: vocabularios y gramáticas formales}

Cuando llegué a la Mixteca de Guerrero el año 1993, con el encargo de realizar un vocabulario del tu’un savi, me encontré con un equipo de jóvenes dedicados a la investigación participativa, que gestionaban en equipo proyectos de diversos ámbitos. Tras conocer y analizar obras como el vocabulario sobre el mixteco de San Miguel el Grande (Dyk y Stoudt, 1965) y el estudio de Marcelo Swadesh y Evangelina Arana (Arana y Swadesh, 1965) sobre el mixteco postclásico, basado en los trabajos de los misioneros dominicos en Teposcolula: Ia Gramática de Fray Antonio de los Reyes y el Vocabulario de Francisco de Alvarado (1593), accedí a las investigaciones de Josserand (1983) acerca de la diversidad dialectal histórica del tu'un savi, imprescindibles para cualquier proyecto de normalización futura (cfr. Martínez Sánchez, 2015: 183-186). En cualquier caso, pude comprobar por mí mismo que las variantes entre Guerrero y Oaxaca no obedecían tanto a criterios geográficos o geolectales, sino a movimientos de población a lo largo de la historia del ñuu savi.

No sería hasta algunos años después, a la vuelta de mi trabajo de campo, debido a las condiciones de extremo aislamiento que padecía la Montaña de Guerrero, cuando tuve acceso a los múltiples y meritorios trabajos del Instituto Lingüístico de Verano que han consolidado la imagen del tu'un savi como una constelación de dialectos, susceptibles de normativizaciones muy diversas. Este hecho pudo deberse también a la dispersión metodológica de sus miembros, quienes hicieron uso de las herramientas gramaticales propias de las corrientes lingüísticas de la época para formalizar los corpus recogidos durante sus trabajos de campo. Aun así, me han sido muy útiles tanto la colección de Sketches, elaborada desde los años 60 a los 90 del pasado siglo sobre distintas áreas dialectales (Bradley y Hollenbach, 1988-1992; cfr. Martínez Sánchez, 2015: 178-179), como los abundantes y prolijos artículos de Elena Erickson de Hollenbach en tiempos más recientes (cfr. Erickson, 2007).

En cuanto a la transcripción de la fonética del tu’un savi, tuve la suerte de contar con las cartillas publicadas por Alonso Solano González para la SEP de Guerrero (SEG), que sirvieron a su vez de fuente para el establecimiento del alfabeto (Ndusu Tu'un Savi) por la Ve'e Tu'un Savi (1997) pocos años después. No obstante, pude comprobar el grave problema que suponía la dispersión de los investigadores y su diferente formación lingüística, con el fin de llegar a un acuerdo sobre una convención ortográfica. 
Así pues, intenté reunir un corpus lo más extenso posible, con los limitados recursos de la época, aunque ignoraba grandes áreas de la cultura del ñuu savi, en la que apenas comenzaba a iniciarme. No existía, aún, ningún software que me ayudara a transcribir, por lo que buscaba inspiración en mis recuerdos sobre la separación y distribución de morfemas, según el estructuralismo norteamericano (Hockett, 1947), y su valor distintivo de acuerdo con el formalismo europeo (Jakobson, Fant y Halle, 1952). Al tratar con una lengua oral, lo más lógico era evitar la traslación de las categorías sintácticas en cuyo análisis me había formado y recurrir a la pragmática lingüística para entender la organización temático-remática, con el mayor apego posible a la intencionalidad de los hablantes (Martínez Sánchez, 2015: 391 y ss.). No llegué a obtener una imagen holística de la sintaxis del tu'un savi hasta mucho tiempo después.

Aunque mi encargo se limitaba a elaborar un vocabulario, deseaba conseguir muestras de todas las palabras posibles en su contexto (cfr. Martínez Sánchez, 2014). A pesar de que me había servido de fiel auxiliar, no pude menos que lamentar la falta de valor práctico de la lingüística académica en la que me había formado. Tanto los misioneros católicos, cuatro siglos antes, como las misiones evangélicas en la contemporaneidad habían producido textos religiosos o doctrinales en tu'un savi, pero dejaron en la oscuridad la memoria cultural e histórica del ñuu savi.

Desde 1994 hasta el año 2000, pude recorrer las comunidades, dar pláticas en tu’un savi sobre derechos humanos y recoger datos para elaborar informes destinados a Amnistía Internacional o participar en proyectos de desarrollo comunitario. Lo paradójico de aquellos y de estos tiempos es que el marco jurídico constitucional proteja la libertad religiosa o que la cultura dominante tolere el proselitismo religioso y elogie los esfuerzos académicos como aportaciones al desarrollo humano, mientras que las leyes que formalmente amparan los derechos de los pueblos originarios no garantizan ni aun la reproducción cultural y vital de sus miembros. Es un hecho que la cultura dominante sigue actuando con intolerancia contra las formas reales de autonomía cultural y política bajo su control. Una de ellas, quizá la más ostensible, es el uso de la lengua en las esferas públicas de la administración, la economía y la política.

Por lo tanto, habrá que plantearse la necesidad de un nuevo pacto entre la investigación académica y los pueblos originarios que acredite a los agentes creadores de cultura como protagonistas de cualquier especie de desarrollo. Por ejemplo: ¿cómo mediríamos el índice de impacto de una publicación científica en tu'un savi, si nos atenemos exclusivamente a criterios impuestos por la globalización? Hace tiempo que los profesionales y universitarios na savi se plantean esa pregunta, cuando se sienten forzados a escribir en castellano o en inglés. Mientras tanto, la vitalidad del tu'un savi se hace ostensible a través de los medios sociales, donde una chilena (género musical del Pacífico Sur mexicano) en mixteco puede alcanzar el millón de visitas. 


\section{La lingüística con que crecimos: aplicación a la didáctica de las lenguas}

La lingüística aplicada y, en particular, la didáctica de las lenguas ha auxiliado, sin duda, los procesos de revitalización lingüística, a lo que hay que sumar el creciente despliegue de las tecnologías lingüísticas. A este respecto, la formación de los docentes en regiones indígenas debe exigir, en alguna medida, una competencia comunicativa en las lenguas originarias como parte de su perfil profesional. Hoy, en 2017, empieza a ser posible usar software o aplicaciones de Android y de IOS que facilitan el aprendizaje de lenguas originarias.

Un buen ejemplo lo proporciona la aplicación “Vamos a aprender mixteco” (http://ccemx. org/labciudadania/category/vamos-a-aprender-mixteco/), de la empresa Manuvo, basada en el libro homónimo de Donato García (2015) sobre el tu’un savi de Santa Inés de Zaragoza (Oaxaca), en cuya financiación ha participado el Laboratorio de Ciudadanía Digital del Centro Cultural de España en México (CCEMx). Es interesante que el CCEMx incluya esta producción, la única dedicada a los pueblos originarios, entre otras decenas de colaboraciones, como fue varias veces demandado (Zimmermann, 2011: 31).

Donato García había preparado el libro como herramienta de un taller de revitalización de la lengua en su pueblo que, posteriormente, se llevó a cabo en la Universidad Tecnológica de la Mixteca, la Universidad Intercultural de los Pueblos del Sur (Malinaltepec, Guerrero) y el Instituto de Investigaciones Antropológicas de la UNAM. Cuando se presentó la aplicación, el autor declaró a la agencia NOTIMEX que el libro "se hizo a través de mis experiencias en mi comunidad de origen, partiendo de mi necesidad de reforzar el habla en las personas, porque noté que ya no existe el interés de hablar, ni aprender la lengua”. Más allá de lo políticamente correcto, el maestro Donato no pierde la oportunidad de denunciar las condiciones de vida que soporta su pueblo, como hizo en la XXVII Feria Internacional del Libro de Antropología e Historia (https://youtu.be/GqDcFoDrLnc).

\subsection{La aporía de la enseñanza de la lengua en una variedad local}

Son muy numerosas las cartillas, los vocabularios o los manuales del tu'un savi en distintas áreas dialectales, tantos como supuestas variantes ha determinado el ILV (cfr. Ia plataforma Ethnologue [Simons y Fennig, 2017], sujeta a suscripción desde hace pocos años: https:// www.ethnologue.com/subgroups/mixtec). Sería injusto afirmar que los investigadores extranjeros no hayan buscado el modo de ser útiles, o que no hayan asesorado a quienes deseaban hacerlo a través de las misiones religiosas en la región. Sin embargo, es constatable que la práctica totalidad de los esfuerzos ha adolecido de una perspectiva global e incluyente sobre el desarrollo del ñuu savi. En palabras de Donato García (2015: 11), "lo más importante será que se inicien talleres de reflexión y análisis, en fin, debates que conduzcan a establecer 
una estructura unificada y poner en práctica el uso cotidiano de nuestra lengua Ñuu Davi, a efecto de dignificar la herencia de nuestros antepasados".

La experiencia de las migraciones a lugares donde confluyen na savi de distintas procedencias y, sobre todo, el impacto de las redes sociales (Youtube, Facebook) están creando el contexto favorable y facilitando los intercambios que no habían previsto los académicos y expertos. El trabajo de los lingüistas podría así estar al servicio de las culturas emergentes en los pueblos originarios, si fuéramos capaces de superar prejuicios como los que señalo a continuación. Crear plataformas de música mixteca (ya’a savi) y subtitular los vídeos en Youtube; acompañar a los migrantes en los lugares donde se establecen, tanto en México como en USA (cfr. Tiburcio y John, 2014; Pérez Castro, 2015) son solo algunas posibilidades muy reales.

\subsection{La paradoja de la interculturalidad en un solo sentido}

Cualquier relación intercultural, incluyendo las que se establecen entre la investigación y la educación, tiene dos caras; una obviedad que no ha condicionado, hasta la fecha, el diseño de los programas elaborados desde la cultura dominante, los cuales se dirigen de forma exclusiva, o de manera poco equitativa, a la integración aculturadora de personas o grupos étnicos diferenciados.

En este sentido, aunque el pueblo na savi haya emprendido una gesta colectiva para mejorar sus condiciones de vida, afrontando condiciones inhumanas: salarios ínfimos, condiciones laborales extenuantes, fronteras cerradas, redes de delincuencia, etc., que una parte muy relevante no pudo superar, se sigue culpando a este y otros pueblos originarios de su pobreza. Por lo que respecta a la lingüística, la insistencia, basada en datos reales pero parciales, sobre la multiplicidad de variedades dialectales del tu’un savi no genera una impresión de riqueza cultural, a diferencia de las pruebas sobre la diversidad en cualquier lengua dominante, sino que refuerza la batería de prejuicios acerca de las lenguas originarias, a las que se continúa denominando "dialectos". Quienes transforman la realidad son algunos na savi cuando asumen la etiqueta proyectada y la revaloran con un nuevo sentido: "mi dialecto", es decir, mi lengua materna.

Así pues, es preceptivo que la interculturalidad tenga cabida en los medios de reproducción de la cultura dominante: en los currículos oficiales de la educación pública y en los departamentos y las áreas de conocimiento universitarios para superar los prejuicios y vencer la ignorancia.

\subsection{La aporía del método: la reducción de la memoria cultural}

No hay ningún modelo de investigación lingüístico que no tenga una faceta pragmática o utilitarista. Las finalidades definen los métodos. El modelo ecléctico que he presentado en mi 
libro Tu’un Savi Ñuu Kuatyi: La lengua mixteca en la Montaña de Guerrero (Martínez Sánchez, 2015) pone de manifiesto un conocimiento parcial de los géneros discursivos que vivifican la lengua "original” (por auténtica), "originaria” (por su carácter histórico y su relación ecológica con el medio) u "originante" (por su trascendencia con respecto a cualquier descripción reductora). El libro está escrito en una lengua dominante (podría ser el inglés o cualquier otra lengua de pasado colonial), pero pretende describir una lengua "originaria" y reconocer la potencia inabarcable del tu’un savi como lengua "originante".

La perspectiva reduccionista de los métodos comienza por la selección de los informantes. La documentación de un corpus nunca será suficientemente amplia, pero todavía es más estrecha cuando no se tiene conciencia de que debe tomar en consideración todos los géneros discursivos que constituyen la lengua originante. He intentado abrir mi propio modelo a la realidad señalando o apuntando hacia lo que debería ser una translingüística, en términos de Mijail Bajtín (1982 [1952-1953]), que pudiera comprender y explicar "las esferas sociales de acción, los géneros discursivos y los marcos cognitivos en los que me inicio a través de la relación con alguien más capacitado" (Martínez Sánchez, 2013: 186).

Cabe anotar, como un hecho positivo y esperanzador, que las descripciones aisladas del tu'un savi en decenas de áreas dialectales pueden ser puestas en relación por un equipo de investigadores que tengan claros los fines de su actividad, al servicio de la normalización de la lengua y la inclusión de todas sus variedades. El método que diseñé para el aprendizaje del tu’un savi como L2 (Martínez Sánchez, 2011) se centró sobre la actividad de los agentes educativos y sanitarios, así como en algunos aspectos de la vida doméstica o comunitaria. Sin embargo, todas las esferas sociales de la cultura ñuu savi se organizan en forma de comunidades de práctica. Todas son igualmente necesarias, aunque algunas tengan mayor relevancia como prototipos de la identidad colectiva (cfr. Martínez Sánchez, 2013: 191-193) y no precisamente las consideradas más útiles por el desarrollismo. Me refiero a los géneros estéticos, como la canción mixteca, yaa savi; así como los rituales desempeñados por "especialistas de la palabra”, un concepto de Walter Ong adoptado por el antropólogo ta savi y líder comunitario Jaime García Leyva (2016), los discursos ceremoniales (López García, 2007) y los etnodramas del diálogo con la lluvia y con las enfermedades, estudiados por Antonio Guerra Arias (2015), quien me ha ayudado a descubrirlos gracias a nuestra colaboración en el proyecto Ndatiaku.

Los estudios que se han hecho desde el cognitivismo se enfocan sobre ciertos espacios mentales del tu’un savi, como la topografía por medio de metáforas cognitivas (las partes del cuerpo humano son la principal matriz de locativos, cfr. Macaulay, 1996; Langacker, 2002) y la semántica de otros argumentos: experimentador, paciente o tema (cfr. Martínez Sánchez, 2015: 82 ss.). Sin duda, sirven para nutrir el debate secular entre relativismo y universalismo, en tanto que sondean el misterio de la articulación entre los principios universales (la sintaxis de los verbos y los argumentos) y los parámetros culturales (la configuración de redes temá- 
ticas en una lengua concreta). A pesar de su interés intrínseco, nos dejan interrogantes sobre la pragmática de la lengua: ¿por qué así y no de otra manera?, ¿cuál es su sentido en el mapa de los géneros discursivos y las esferas sociales del tu'un savi?

En cuanto al trabajo etnográfico, las fuentes disponibles dan acceso a decenas de cuentos populares, transcritos o adaptados, que son útiles para el aprendizaje de la lengua. Sin embargo, escasean las referencias a la memoria cultural, expresada en mitos y ritos (cosmovisión indígena: Ios mitos de origen, cfr. Villela, 2009), que exige a los investigadores una actitud participativa y un compromiso con la supervivencia y el empoderamiento del ñuu savi, frente al descrédito de sus tradiciones por imperativos religiosos o políticos. La reciente publicación de Jaime García Leyva, Na Savi: gente de la lluvia (2016), donde resume sus preocupaciones antropológicas durante dos décadas, saca a la luz los vínculos entre la historia social, las memorias colectivas, las identidades culturales y la lengua.

Por su parte, Ofelia Pineda Ruiz ha trazado su propio itinerario de búsqueda, comenzando por colaborar en la interpretación de los códices mixtecos con el equipo de Marteen Jansen y Aurora Pérez Jiménez (2009), de la Universidad de Leiden. Su compromiso por defender la continuidad del ritual de la Lluvia en El Jicaral (Ñuu Tiaxin, Oaxaca), así como por recuperar tradiciones ancestrales (Pineda Ruiz, 2012), le llevó a intervenir en las investigaciones de Antonio Guerra y a cooperar como protagonista en el proyecto Ndatiaku (Pineda Ruiz, 2014).

La perspectiva de género en la lengua es un mundo por descubrir que apenas he podido atisbar en mis investigaciones sobre los morfemas clasificadores (determinantes, pronombres, nexos; cfr. Martínez Sánchez, 2015: 50). No se puede achacar, en este caso, a una perspectiva reductora de la lingüística aplicada sobre las lenguas originarias, sino a la percepción que los mismos hablantes tienen de que el tu'un savi organiza los prototipos cognitivos de su sintaxis, la semántica de sus enunciados, el conjunto referencial de sus textos y los mundos posibles de su imaginario para representar una cosmología mucho más horizontal y diversificada que la indoeuropea, sea de raíces latinas o germánicas (cfr. Martínez Sánchez, 2015: 49 y ss.; 191 y ss.).

En contraste con la clasificación referencial por géneros en castellano (diádica: masc. y fem. + pl.) o en alemán (triádica: masc., fem. y neut. + pl.), en tu’un savi se diferencian seis o más prototipos de referencia (masc./líquido, fem., hum. genérico en pl., animal/redondo, materia/ planta, neut.), que intervienen en la conjugación junto con cuatro prototipos pragmáticos de relación comunicativa ( $1 .{ }^{a}$ persona del singular y del plural, 2. ${ }^{a}$ p. sing. y pl., 3. ${ }^{a}$ p. de las seis clases citadas, además del determinante inclusivo yoo). Así pues, los determinantes personales (con distintas funciones: determinante, pronombre, nexo) forman un conjunto de once categorías (cinco para el castellano) en una red compleja de valores sintácticos, semánticos y pragmáticos. 
Así y todo, la organización de los géneros discursivos en diversas esferas sociales revela una estructura social patriarcal, como resultado de la discriminación en el acceso de las mujeres a determinados cargos políticos o las fronteras de género entre el espacio doméstico y el espacio público. Hay que investigar la correspondencia de los argumentos sintácticos y las funciones narrativas con los roles sociales distribuidos por géneros sexuales (cfr. Martínez Sánchez, 2014: 195), fundamentalmente, si se quieren entender los cambios sociolingüísticos y los efectos sobre la lengua de una progresiva emancipación de las mujeres.

\section{El movimiento indígena como marco de investigación-acción participativa}

De acuerdo con lo dicho anteriormente, parece claro que cualquier esfuerzo por revitalizar una lengua sujeta a amenazas como las arriba descritas tiene que comenzar por una documentación lo más exhaustiva posible de sus géneros discursivos. Ahora bien, ¿es coherente, además de eficaz, documentar una lengua en el siglo XXI sin dirigirse de forma simultánea, 0 sucesiva, a su revitalización? ¿Cómo podemos escapar de la trampa del neocolonialismo, que reincide en la tentación de decorar su museo real o virtual con huellas de los pueblos amenazados, al mismo tiempo que los despoja de sus territorios y desintegra sus bases sociales y culturales?

Contra todo pronóstico, es un hecho que el golpe planificado por el TLCAN fue respondido por el movimiento indígena en México, tomando pie en la revolución zapatista, a través de una progresiva recuperación de espacios públicos para el uso de las lenguas originarias y el desarrollo cultural en viejos y nuevos géneros discursivos.

Cuando se plantea el desafío de revitalizar las lenguas nativas de México, Klaus Zimmermann coincide con las profesoras Rebeca Barriga, del Colegio de México, y Frida Villavicencio, del CIESAS (cfr. Zimmermann, 2011: 26-27), en que no basta con reunir y difundir un corpus literario o, actualmente, digital (corpus planning); ni tampoco, aunque sea imprescindible, con garantizar la igualdad de estatus en las leyes (status planinng). La prioridad se localiza en promover el uso de la lengua (cfr. todavía con más rotundidad, Avilés, 2016), así como en incidir sobre políticas no estrictamente lingüísticas, que garanticen la viabilidad de los mundos sociales y las esferas de comunicación en la lengua nativa: "Desde el punto de vista de darle a una lengua la posibilidad de 'gozar de vida' es indispensable garantizar una colectividad que la hable. Otorgar un derecho lingüístico sin garantizar la condición social de su existencia significa reducir este derecho a un derecho vacío" (Zimmermann, 2011: 31-32).

Para hacer realidad el derecho a la lengua y al desarrollo de todas las capacidades culturales, en beneficio tanto de los pobladores como de sus vecinos próximos o lejanos, sería necesario, previamente, que se verificase la cooficialidad del tu’un savi y las demás lenguas 
originarias con el español en un territorio donde sea aceptable y aceptada por sus habitantes (cfr. Giovine Yáñez, 2008). A su vez, la viabilidad de la Ley de Derechos Lingüísticos del año 2003 en México depende del grado de autonomía administrativa que se reconozca a los territorios indígenas. Solo una administración realmente autónoma podría organizar una planificación lingüística real, que comience el arduo proceso de normalizar las lenguas originarias.

La Academia de la lengua mixteca (Ve'e Tu’un Savi), surgida en 1997 (cfr. Caballero Morales, 2014; Pérez Castro, 2015; García Leyva, 2016: 124-132), contribuyó a tomar conciencia de la nueva situación que ha resultado de los procesos migratorios masivos. Algunos de sus miembros han participado en talleres de escritura organizados por la Universidad Estatal de San Diego, California, "a través de su programa de enseñanza del idioma para estudiantes latinos” (Julián, 2012: 202). También se han promovido talleres de creatividad literaria entre las comunidades ñuu savi asentadas desde hace décadas en Tijuana, Baja California (Pérez Castro, 2008). Lo más importante ha sido incorporar a las aspiraciones colectivas del pueblo na savi una conciencia exigente de la norma común y la lucha constante por aumentar la inteligibilidad entre las regiones de lengua tu'un savi.

Desde junio del 2011, gracias a un trabajo coordinado en red de profesionales, docentes y autoridades na savi, se abrieron cauces participativos para hacer viable la normalización lingüística en el estado de Guerrero, a la vez que se prefiguraba una autonomía política. Ambos son procesos simultáneos de madurez y empoderamiento.

Se comenzó por convocar una serie de talleres en Chilpancingo, capital del estado, con el respaldo de diversas instituciones: INALI, IEEJA, SEG/DEI, durante los meses de junio, septiembre y noviembre del 2011. La mayoría de los asistentes eran miembros de Ve’e Tu’un Savi: Gabriel Caballero, Alonso Solano, Ubaldo López, Juan Julián Caballero, Vicente P. Casiano, Rey Castillo, Amadeo Guadalupe, etc., algunos de los cuales habían comenzado el camino de la normalización en los años 70 del pasado siglo (cfr. García Leyva, 2016: 126-129). Los debates del taller se nutrieron de la experiencia vivida por sus miembros en Ve'e Tu'un Savi: las bases normativas para la escritura (Ve'e Tu’un Savi, 2007) y el Diplomado “Tu’un Savi e Identidad” (Ve'e Tu’un Savi, 2012).

La legalidad a la que aspiran los ñuu savi, en armonía con los demás pueblos originarios, será un producto de la democracia y la soberanía popular; pero no es posible legislar el uso de las lenguas, sino las condiciones óptimas para su uso. A esa dimensión se han referido los cinco congresos de tu'un savi en el estado de Guerrero, entre 2011 y 2017 (cfr. García Leyva, 2016: 132-135), coordinados por el Comité de Desarrollo Lingüístico, que son el fruto y el desencadenante de un movimiento sociocultural en favor de la lengua autóctona. El lema común de su convocatoria ha sido: nandiko yó nuú tio’o yó, ta kixa’a yó kua’nu yó, "Volvamos a nuestras raíces, para empezar a florecer". En palabras de Jaime García, "fortalecer la cultura, la lengua y la identidad requiere de la recuperación de la historia propia, usando instrumentos como las nuevas tecnologías de información y comunicación” (García Leyva, 2016: 135). 
Tuve ocasión de participar como invitado en el primer Congreso de Desarrollo LingüístiCo, los días 12 y 13 de octubre del año 2011. Después de once años que salí de Rancho Xa’á Democracia (Rancho Nuevo de la Democracia), fui testigo de una nueva etapa en el movimiento indígena, rodeado por una muchedumbre de maestras y maestros que se comprometían a reconstruir su identidad cultural.

El único modo de mantener el contacto después de aquel reencuentro han sido las redes sociales. Cuando se organizó el proyecto Ndatiaku Tu’un Savi, gracias al entusiasmo compartido con Juan Pablo Mora, Antonio Guerra y Ofelia Pineda, se confirmó la certeza de que cualquier iniciativa en favor de las lenguas originarias tenía que entrar por una doble puerta y un espacio diáfano: acompañar los procesos de revitalización de la lengua y la cultura impulsados por los propios na savi, situando a sus protagonistas en el centro de un escenario virtual, además de poner en contacto directo a los jóvenes estudiantes con los hablantes reales y conscientes de su lugar en el mundo.

Tampoco es casual la coincidencia histórica entre el proyecto Ndatiaku y los movimientos sociales que impulsan una visión crítica del pasado imperial y el presente neocolonial en España y Europa. Frente a la persistencia o el agravamiento de las estrategias de dominio por parte de los poderes financieros y sus subalternos políticos, que han aprovechado la crisis económica mundial para consolidar las desigualdades y profundizar las fronteras políticas y étnicas, necesitábamos reconocer y asumir los ejemplos de resistencia indígena a los intentos de negar su identidad y desposeer a los pueblos originarios, no solo de su lengua y su cultura, sino también de su territorio, y aun del derecho al territorio, a lo largo de más de 500 años.

Desde el año 2015, hemos iniciado una nueva fase del proyecto Ndatiaku que se orienta de manera específica a formar estudiantes para la documentación de las lenguas como parte de su revitalización, lo que desearíamos profundizar en el futuro. En términos generales, seguimos soñando con dar continuidad al proyecto y abrir brecha en el panorama universitario, que ha olvidado la relevancia de las lenguas originarias amerindias en un mundo compartido desde hace cinco siglos, si se exceptúan las investigaciones sobre el contacto entre lenguas en la sociolingüística del español de América (Zimmerman, 2001; Flores Farfán, 2013) y los equipos representados en el presente número de la revista Onomázein.

\section{Conclusión}

La defensa y la promoción de los derechos humanos y ecológicos obliga a replantear el sistema de alianzas entre los agentes sociales internacionales. Los pueblos originarios ya no deben ser tratados como meros comparsas en foros sociales mundiales, sino que constituyen el paradigma de la resistencia contra la destrucción acelerada de la Madre Tierra, dado lo 
poco que han podido lograr el ciberactivismo, las organizaciones no gubernamentales internacionales o la Organización de Naciones Unidas, en sus intentos por minimizar los riesgos y compensar las amenazas.

El término "revitalización” quizá sea insuficiente para resignificar las prácticas vernáculas y revalorar las formas de organización y autogestión que han recuperado algunos espacios públicos: los medios sociales o la administración, cuando se ha hecho con criterios distintos de las ideologías dominantes. Así se hace patente al investigar las denuncias contra el extractivismo en América Latina (cfr. Pineda Ruiz y otros, 2017) o la continuidad entre los géneros vernáculos y los géneros digitales, que hacen perceptible la energía de las lenguas originarias y originantes (cfr. Avilés y Martínez Sánchez, 2017). Habría que hablar de resistencia y de estrategias solidarias con quienes resisten, a diferencia de aquellas prácticas que ya no son útiles para la emancipación y la vida de seres autónomos. Ocupémonos, pues, del impacto (material, cultural) que puedan tener en las próximas generaciones nuestros estilos de vida (hábitos de pensamiento y acción: habitus, en términos de Pierre Bourdieu) y nuestras formas de cooperación y servicio, a la vez que estudiamos la realidad de las lenguas originarias en sus géneros discursivos: participantes comprometidos en un diálogo y un aprendizaje de por vida.

\section{Bibliografía citada}

Arana, Evangelina, y Mauricio SWAdesh, 1965: Los elementos del mixteco antiguo, México: Instituto Nacional Indigenista e Instituto Nacional de Antropología e Historia.

Avilés Gonzalez, Karla J., 2016: Desafíos de la reivindicación nahua en Santa Catarina, Tepoztlán, Morelos, Paris: Michel Houdiard Editeur.

Avilés González, Karla J., y Joaquín J. Martínez Sánchez, 2017: "Métodos para documentar y revitalizar las lenguas amenazadas en las redes sociales", taller en el Primer Congrés Internacional sobre Revitalització de Llengües Indígenes i Minoritzades, Barcelona y Vic: Universitat de Barcelona - Universitat de Vic - Indiana University, 19-21 de abril [http://dicciomixteco.wixsite. com/ndatiaku/single-post/2017/04/17/M\%C3\%Agtodos-para-documentar-y-revitalizar-laslenguas-amenazadas-en-los-medios-digitales-y-en-las-redes-sociales].

Bajtin, Mijail, 1982 [1952-1953]: "El problema de los géneros discursivos", en Mijail Bajtín, Estética de la creación verbal, México: Siglo XXI, 248-293.

BerRY, John W., 1997: "Immigration, Acculturation, and Adaptation”, Applied Psychology 46 (1), 5-34.

Bradley, C. Henry, y Barbara E. Hollenbach (eds.), 1988-1992: Studies in the syntax of MIxtecan languages, Dallas: Summer Institute of Linguistics and the University of Texas at Arlington, 4 vols. 
Caballero Morales, Gabriel, 2014: Videoconferencia, Ndatiaku Tu’un Savi [http://dicciomixteco. wixsite.com/ndatiaku/single-post/2014/05/22/Gabriel-Caballero-Morales].

Castells, Manuel, 2005 [1996-1998]: La era de la información, 1. La sociedad red, quinta edición, Madrid: Alianza.

Castells, Manuel, 2003 [1996-1998]: La era de la información, 2. El poder de la identidad, tercera edición, Madrid: Alianza.

Castells, Manuel, 2006 [1996-1998]: La era de la información, 3. Fin de milenio, cuarta edición, Madrid: Alianza.

Dyk, Anne, y Betty Stoudt, 1965: Vocabulario mixteco de San Miguel el Grande, México: Instituto Lingüístico de Verano (ILV)-SEP.

Erickson de Hollenbach, Elena, 2007: "Difrasismos mixtecos: del siglo XVI al siglo XXI", UniverSOS, 4, 157-173.

Fishman, Joshua A., 1991: Reversing Language Shift: Theory and Practices of Assistance to Threatened Languages, Clevedon: Multilingual Matters.

Fishman, Joshua A. (ed.), 2001: Can Threatened Languages Be Saved? Reversing Language Shift Revisited: A 21st Century Perspective, Clevedon: Multilingual Matters.

Flores Farfán, José Antonio, 2013: "El español en contacto con lenguas indígenas mexicanas. Documentación, descripción y cuestiones aplicadas" en VV. AA.: Estudios hispánicos en el sig/o XXI, Facultad de Filología, Universidad de Belgrado [http://www.fil.bg.ac.rs/wp-content/ uploads/obavestenja/iberijske/ehes21/28\%20Jose\%20Antonio\%20Flores\%20Farfan.pdf].

García García, Donato, 2015a: Vamos a aprender mixteco, app de Manuvo para Android e IOS, México: Laboratorio Digital, CCEMx [http://ccemx.org/labciudadania/category/vamos-aaprender-mixteco/].

Garcia García, Donato, 2015b: Presentación de su libro "Vamos a aprender mixteco" en XXVII Feria Internacional del Libro de Antropología e Historia, pedagogia.mx [https://www.youtube. com/watch?v=GqDcFoDrLnc].

Garcia Leyva, Jaime, 2016: Na Savi: gente de la Iluvia, México, Conaculta.

Giovine Yañez, María Andrea, 2008: "La diversidad etnolingüística en México en el marco de la Ley General de Derechos Lingüísticos de los Pueblos Indígenas", comunicación presentada en IV Congreso Internacional: El español, lengua de traducción para la cooperación y el diálogo, Universidad de Castilla-La Mancha [http://cvc.cervantes.es/lengua/esletra/ pdf/04/045_giovine.pdf]. 
Guerra Arias, Antonio, 2015: Estoy aprendiendo la palabra de bienestar: Kutü'và yu tu’ún va'á. Iniciación etnodramática, Madrid: Universidad Complutense de Madrid (tesis doctoral) [https:// drive.google.com/open?id=0B8AyGFKSOlazWUpoYIRienlyNjQ].

Habermas, Jürgen, 1987: Teoría de la acción comunicativa, 2 vols., Madrid: Taurus.

Hockett, Charles F., 1947: "Problems of Morphemic Analysis" en Language 23 (4), 321-343 [http:// www.jstor.org/stable/410295?seq=1\#page_scan_tab_contents].

Jakobson, Roman, Gunnar Fant y Morris Halle, 1952: Preliminaries to Speech Analysis: the Distinctive Features and their Correlates, Cambridge, Ma., MIT Press [http://www.speech.kth.se/ gunnarfant/Jakobson_Fant_Halle_Preliminaries_to_Speech_Analysis.pdf].

Jansen, Maarten, y Aurora Pérez Jiménez, 2009: La lengua señorial de Ñuu Dzaui: Cultura literaria de los antiguos reinos y transformación colonial, Oaxaca: Secretaría de Cultura - Universidad de Leiden.

JoRnadas Na Savi, 2014: Jornadas sobre el Desarrollo Sostenible del Ñuu Savi: el factor lingüísticocultural, Sevilla: Universidad de Sevilla, 17-19 de octubre de 2014 [http://dicciomixteco.wix. com/jornadasavi].

Josserand, Judy Kathryn, 1983: Mixtec Dialect History, Nueva Orleans, Tulane University (tesis doctoral).

Julián Caballero, Juan, 2012: Ñuu Davi Yuku Yata: Comunidad, identidad y educación en la Mixteca. Tesis doctoral, Universidad de Leiden [https://www.openaccess.leidenuniv.nl/bitstream/1887/14026/1/J+Julian+Caballero+Dissertatie.pdf].

LANGACKER, Ronald W., 2002: "A Study in Unified Diversity: English and Mixtec Locatives" en N. J. Enfield (ed.): Ethnosyntax: Explorations in Grammar and Culture, Oxford: Oxford U.P., 138-161.

Lewis, Paul, y Gary F. Simon, 2009: “Assessing Endangerment: Expanding Fishman's GIDS”, Revue Roumaine de Linguistique 55 (2), 103-120.

López Garcia, Ubaldo, 2007: Sa'vi: Discursos ceremoniales de Yutsa To'on (Apoala). Tesis doctoral, Universidad de Leiden [https://openaccess.leidenuniv.nl/bitstream/1887/12463/1/01.pdf].

Macaulay, Monica Ann, 1996: A Grammar of Chalcatongo Mixtec, Berkeley: University of California.

Martínez Sanchez, Joaquín José, 2011: Introducción al mixteco vivo: breve corpus de la lengua mixteca en la Montaña mixteco-amuzga (Guerrero, Méx.). Didáctica y podcast para el aprendizaje del Tu’un Savi, en tuunsavi.weebly.com [http://tuunsavi.weebly.com/el-aprendizaje-dela-lengua.html]. 
Martínez SAnchez, Joaquín José, 2012: "El mundo vital na savi: ña yuvi nu iyo na yuvi. Los recursos naturales de la Montaña en sus marcos culturales" en IV Coloquio de la Mixteca: Economía y Recursos Naturales de los pueblos mixtecos: del periodo precolombino al mundo globalizado, México, CIESAS [http://tuunsavi.weebly.com/mundo-vital-del-ntildeuu-savi-en-guerreromeacutexico.html].

Martínez SAnchez, Joaquín José, 2013: “Memoria cultural y lenguaje: el tu’un savi de Guerrero, México", UniverSOS 10, 185-201 [http://tuunsavi.weebly.com/el-aprendizaje-de-la-memoria.html].

Martínez Sanchez, Joaquín José, 2014: Diccionario de Tu’un Savi en el área dialectal de la Montaña mixteco-amuzga, en tuunsavi.weebly.com [http://tuunsavi.weebly.com/diccionario-de-tuunsavi.html].

Martínez SAnchez, Joaquín José, 2015: La lengua mixteca en la Montaña de Guerrero: la identidad amenazada de un pueblo migrante, Alicante: Publicacions Universitat d’Alacant.

Ninyoles, Rafael, 1971: Idioma i prejudici, Ciutat de Palma: Moll.

Pérez Castro, Tiburcio, 2008: Tu’un ñochi si tu’un savi (producción literaria en lengua mixteca), México: INALI.

Pérez Castro, Tiburcio, 2015: “Plática con Tiburcio Pérez Castro” en Ndatiaku Tu’un Savi [http:// dicciomixteco.wix.com/ndatiaku\#!PI\%C3\%Aュtica-con-Tiburcio-P\%C3\%Agrez-Castro/c1aod/55 e258980cf2dego2a78891e].

Pineda Ruiz, Ofelia, 2012: "Entrevista sobre la muerte y el señor de la lluvia en la Mixteca" en Ndatiaku Tu'un Savi [http://dicciomixteco.wix.com/ndatiaku\#!Ndatuun-na-xaa-ña-ni-xìin-yoosatu-ra-Savi-yoo-ku-ra-ka/c1aod/5730d4800cf20cbfb2962243].

Pineda Ruiz, Ofelia, 2014: Curso sobre la lengua (tu'un savi) y la cultura del Ñuu Savi, Universidad de Sevilla, en Ndatiaku Tu'un Savi [http://dicciomixteco.wix.com/ndatiaku\#!Curso-sobrela-lengua-tuun-savi-y-la-cultura-del-Ñuu-Savi-por-Ofelia-Pineda/c1aod/58083A49-41E4-47439131-55A49C298AoA].

Pineda Ruiz, Ofelia, Carmen Alegría Domínguez Ponce, María Fernandez Álvarez, Jaime García Leyva, Juan Pablo Mora Gutiérrez y Joaquín J. Martínez SÁnchez, 2017: "Del extractivismo cultural y lingüístico a la revitalización de las lenguas" en Congreso Internacional sobre el Extractivismo en América Latina: Dimensiones económicas, sociales, políticas y culturales, Sevilla: IEAL, Universidad de Sevilla, 10-12 de mayo [http://dicciomixteco.wixsite.com/ndatiaku/single-post/2017/05/10/C\%C3\%B3mo-afecta-el-extractivismo-a-la-vida-y-la-palabradel-\%C3\%91uu-Savi].

Rendueles, César, 2015: Capitalismo canalla: una historia personal del capitalismo a través de la literatura, Barcelona: Seix-Barral. 
Simons, Gary F., y Charles D. Fennig (eds.), 2017: Ethnologue: Languages of the World, vigésima edición, Dallas, Texas: SIL International [http://www.ethnologue.com/subgroups/mixtec, fecha de consulta: 22 de agosto, 2017].

Tiburcio Solano, Hermelinda, y Emily John Martin, 2014: "Uvi na sií na ndikii na tu'u Na Savi: Hermelinda xii Emily" en Ndatiaku Tu'un Savi [http://dicciomixteco.wix.com/ndatiaku\#!Uvi-na-sií-nandikii-na-tuu-Na-Savi-Hermelinda-xii-Emily/c1aod/114F4522-208F-4CA1-BE95-A7F4A5A4CE21].

TLACHINOLLAN, 2010: Informe XVI: Luchas para construir el amanecer de la justicia, Tlapa: CDHM Tlachinollan.

UNESCO, 2003: "Vitalidad y peligro de desaparición de las lenguas”, Reunión Internacional de Expertos sobre el programa de la UNESCO Salvaguardia de las Lenguas en Peligro, París, 10-12 mar. [http://unesdoc.unesco.org/images/0018/001836/183699S.pdf].

Vée Tu'un SAvi, 2007: Ndusu Tu'un Savi. Bases para la escritura de Tu’un savi, Huajuapan de León: Dirección General de Culturas Populares e Indígenas (DGCPI) - Secretaría de Cultura del Gobierno de Oaxaca.

Vée Tu'un SAVI, 2012: Tu'un Savi e Identidad. Memoria del diplomado: "Uso, lectura, escritura y gramática de la lengua”, Oaxaca: Culturas Populares, Comisión Nacional para el Desarrollo de los Pueblos Indígenas (CDI).

Villela Flores, Samuel Luis, 2009: “Cosmovisión indígena” en PUMC y SAI: Edespig, México: SIPIGUNAM, 465-507 [http://www.nacionmulticultural.unam.mx/edespig/diagnostico_y_perspectivas/diversidad_etnica/1\%20DIVERSIDAD\%20ETNICA\%20Y\%20LINGUISTICA/4\%20COSMOVISION\%2OINDIGENA/Estado\%20del\%20desarrollo\%20(Cap\%2013).pdf].

WalleRstein, Immanuel, 1979 [1974]: El moderno sistema mundial, I. La agricultura capitalista y los orígenes de la economía-mundo europea en el siglo XVI, Madrid: Siglo XXI.

Wallerstein, Immanuel, 1984 [1980]: II. El mercantilismo y la consolidación de la economía-mundo europea, 1600-1750, Madrid: Siglo XXI.

WalleRstein, Immanuel, 1998 [1989]: III. La segunda era de gran expansión de la economía-mundo capitalista, 1730-1850, Madrid: Siglo XXI.

Zimmermann, Klaus, 2001: "El contacto de las lenguas amerindias con el español en México", comunicación presentada en I/ Congreso Internacional de la Lengua Española, Valladolid, 1619 oct. [http://congresosdelalengua.es/valladolid/ponencias/unidad_diversidad_del_espanol/4_el_espanol_en_contacto/zimmermann_k.htm].

Zimmermann, Klaus, 2011: "Reflexiones acerca de la revitalización de las lenguas indígenas en México”. Comentarios de Rebeca Barriga-Villanueva, Juan Carlos Gozenzzi y Frida Villavicencio. Réplica del autor, Universos 8, 9-62. 